\title{
Photosynthesis and net primary productivity in three Antarctic diatoms: possible significance for their distribution in the Antarctic marine ecosystem
}

\author{
K. Petrou* , P. J. Ralph \\ Plant Functional Biology and Climate Change Cluster and School of Environment, University of Technology, Sydney, \\ PO Box 123, Broadway, New South Wales 2007, Australia
}

\begin{abstract}
Photosynthesis and net primary productivity were measured in 3 Antarctic diatoms, Fragilariopsis cylindrus, Pseudo-nitzschia subcurvata and Chaetoceros sp., exposed to rapid changes in temperature and salinity representing a range of conditions found during a seasonal cycle. Measured differences in fluorescence-derived photosynthetic activity and oxygen evolution suggested that some alternative electron cycling activity was present under high irradiances. $F$. cylindrus displayed the highest rates of relative electron transport and net primary productivity under all salinity and temperature combinations and showed adaptive traits towards the sea-icelike environment. P. subcurvata displayed a preference for low saline conditions where production rates were greatest. However, there was evidence of photosynthetic sensitivity to the lowest temperatures and highest salinities, suggesting a lack of adaptation for dealing with sea-ice-like conditions. Chaetoceros sp. showed high plasticity, acclimating well to all conditions but performing best under pelagic conditions. The study shows species-specific sensitivities to environmental change, highlighting photosynthetic capacity as a potentially important mechanism in ecological niche adaptation. When these data were modelled over different seasons, integrated daily net primary production was greatest under summer pelagic conditions. The findings from this study support the general observations of light control and seasonal development of net primary productivity and species succession in the Antarctic marine ecosystem.
\end{abstract}

KEY WORDS: Net primary productivity - Antarctic diatoms - Ecological niche adaptation · Chl a fluorescence

Resale or republication not permitted without written consent of the publisher

\section{INTRODUCTION}

Numerous studies have linked phytoplankton physiology with ecological adaptation (Sakshaug et al. 1987, Strzepek \& Harrison 2004, Bailey et al. 2008). Such studies have found that the photosynthetic architecture and physiology of species can differ greatly, and adaptive traits can be linked to the species' ability to inhabit and often dominate a particular ecological niche, including niche occupancy as a function of light (Sakshaug et al. 1987, Lavaud et al. 2007), iron availability (Strzepek \& Harrison 2004, Bailey et al. 2008, Mackey et al. 2008) and photoprotective capacity (Dimier et al. 2009). In particular, the ecological success of diatoms has been linked with a high photosynthetic flexibility, allowing this class of microalgae to outcompete other phytoplankton groups, especially in environments where light is variable (Kashino et al. 2002, Wagner et al. 2006). Indeed, even within the diatom group, there have been measurable differences in short-term acclimation strategies and photoprotective capacity between individual species from different environments (Dimier et al. 2007, Lavaud et al. 2007). The large diversity in diatom physiological plasticity and ecological niche selectivity suggests that Antarctic diatoms in general should be adapted to such variable and extreme conditions and, therefore, should 
display high photoprotective capabilities. However, it is unknown whether differences in photoprotective capacity among Antarctic diatom species can be linked with specific niche environments.

Antarctic marine phytoplankton are exposed to large changes in ecosystem conditions during an annual cycle (Fig. 1). In winter, phytoplankton are rapidly incorporated into the sea ice matrix where they are confined to tiny brine channels (salinities up to 145) at freezing temperatures (Gleitz \& Thomas 1992). Initially incoming solar irradiance is very high in the developing sea ice, as a result of being constrained close to the surface, but as the ice thickens, irradiance declines, often to levels of less than $1 \%$ surface irradiance (Palmisano et al. 1987). In the austral spring, the ice begins to melt, and the microalgae are washed out of the brine channels into a surface lens of hyposaline water. The meltwater environment, characterised by low salinities (typically below 33), a stable water column and shallow mixed layer, forms an ideal environment for the development of phytoplankton blooms (Dierssen et al. 2002). In summer, the Southern Ocean mixes phytoplankton from the surface waters to the deep, delivering a moderate and variable light environment, warmer tempera- tures and moderate salinity (Fig. 1). All of these shifts in light, temperature and salinity can have a profound effect on phytoplankton growth rates (Aletsee \& Jahnke 1992) and carbon assimilation (Thomas \& Gleitz 1993). High carbon turnover has been associated with fast-growing Antarctic diatoms (Thomas \& Gleitz 1993) and growth rates under low-temperature and high-salinity conditions have been shown to differ between Antarctic diatom species (Aletsee \& Jahnke 1992). Therefore, it follows that photosynthesis under different environmental conditions will be species-specific; this, in turn, would result in differences in species' contributions to the community net primary productivity (NPP).

Traditionally, ${ }^{14} \mathrm{C}$-uptake and oxygen evolution were used to estimate primary production and photosynthesis (Juneau \& Harrison 2005). However, in recent decades, chlorophyll a (chl a) fluorescence has been a popular technique employed to investigate the photophysiology of plants (Krause \& Weis 1991). Several studies have found a good correlation between fluorescence-derived relative electron transport rates with primary productivity measured as oxygen evolution or carbon fixation under low light conditions (Prasil et al. 1996, Geel et al. 1997,

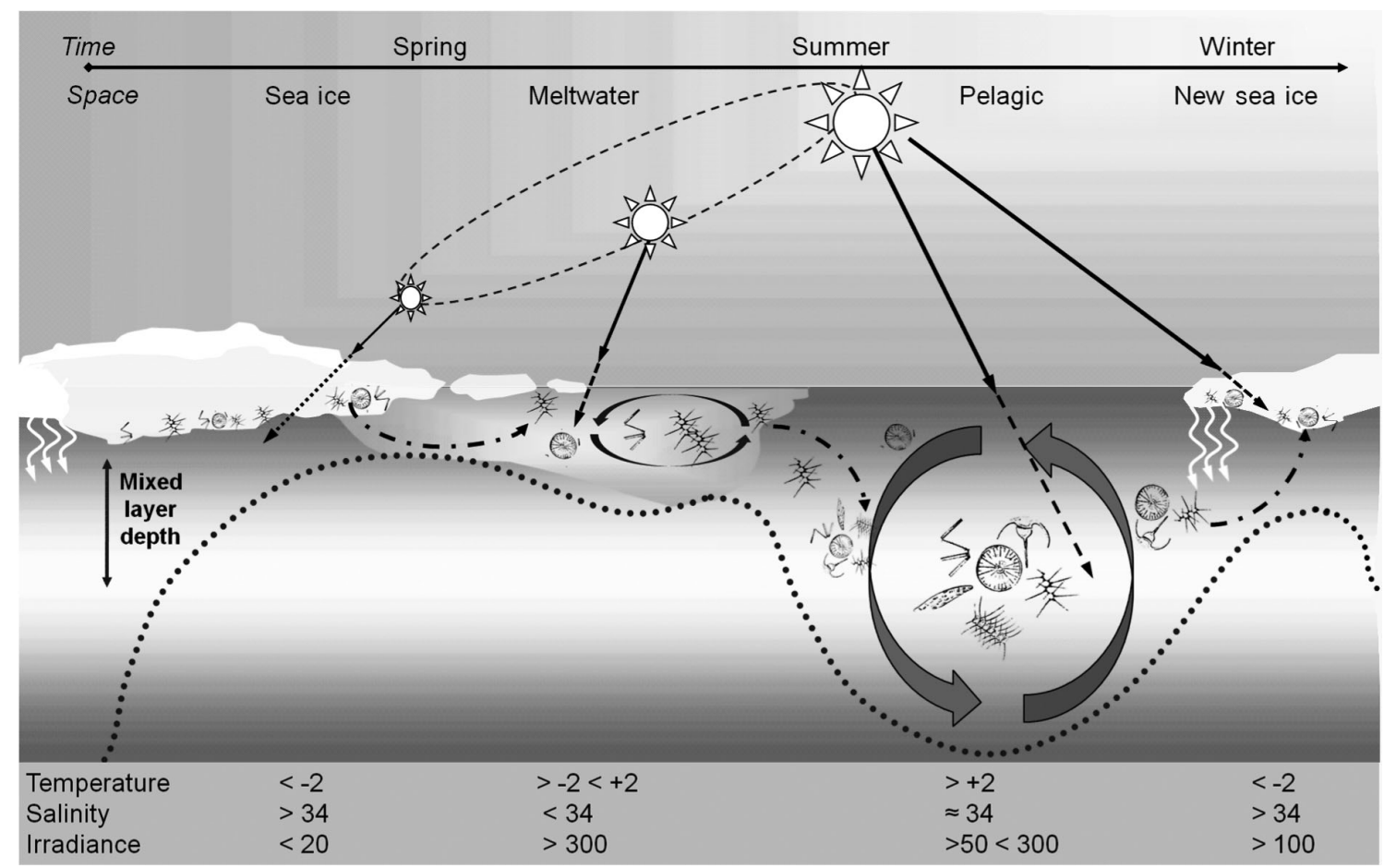

Fig. 1. Spatial and temporal evolution and decay of sea ice in the Antarctic marine ecosystem. Mixed layer depth ( $\cdots \cdot \cdot)$ and light attenuation (----) are depicted. The seasonal pathway of phytoplankton (-.-.-.) from the winter sea ice to the meltwater and pelagic environments is shown. Temperature $\left({ }^{\circ} \mathrm{C}\right.$ ), salinity and irradiance (in $\mu$ mol photons $\mathrm{m}^{-2} \mathrm{~s}^{-1}$ ) properties for each environment are tabulated. Adapted from Eicken (1992) 
Masojídek et al. 2001). In all cases, linearity disappears beyond light saturation levels, resulting in fluorescence data vastly overestimating primary production (Gilbert et al. 2000). In diatoms, there have been several alternative electron pathways, not leading to carbon fixation, suggested as possible reasons behind this discrepancy, including cyclic electron transport around Photosystem II (PSII) (Prasil et al. 1996, Lavaud et al. 2002), cyclic electron transport around Photosystem I (PSI) (Bendall \& Manasse 1995) and the water-water cycle (Geel et al. 1997).

The physical and biological processes associated with the seasonal formation and decay of sea ice is what shapes Antarctic phytoplankton communities, determining colonisation, growth, succession, grazing and, ultimately, productivity. This study investigates short-term acclimation in photosynthesis and NPP in 3 Antarctic diatoms exposed to rapid shifts in temperature and salinity simulating transient environmental conditions of seasonal relevance (sea ice, meltwater and pelagic environments). It measures NPP (measured as oxygen evolution) and electron transport efficiency (measured using chl a fluorescence), and investigates species-specific physiological sensitivities to rapid changes in temperature and salinity. Furthermore, it discusses how this may influence species-specific contributions to overall primary productivity within the Antarctic marine ecosystem. It is hypothesised that species known to dominate a particular niche environment will show physiological adaptation and rapid acclimation to those conditions. NPP will vary between species under different environmental conditions, and species displaying a low photosynthetic plasticity will express photosynthetic sensitivity to conditions outside their preferred ecological niche.

\section{MATERIALS AND METHODS}

Cultures and sampling. The Antarctic diatom Fragilariopsis cylindrus (Grunow) was collected from ice cores $\left(66^{\circ} \mathrm{S}, 147^{\circ} \mathrm{E}\right)$ taken in November 2001, Chaetoceros sp. was isolated from East Antarctic coastal waters and Pseudo-nitszchia subcurvata (Hasle) Fryxell PS71/60-1 Plate II B1 was collected from the subpolar South Atlantic ocean $\left(58^{\circ} \mathrm{S}\right)$. Diatoms were cultured in natural seawater (salinity 34) enriched with $F / 2$ nutrients in specialised glass bottles (approx. 1 l) under continuous air bubbling and maintained at $+4^{\circ} \mathrm{C}$ (Guillard \& Ryther 1962). Light was supplied at $50 \mu \mathrm{mol}$ photons $\mathrm{m}^{-2} \mathrm{~s}^{-1}$ (Grolux, GMT Lighting) on a 16:8 h light:dark cycle.
For simplicity, one moderate light level was used in all treatments throughout the experiment to avoid confounding any responses to the salinity and temperature treatments. Once reaching exponential growth phase, measured using in vivo fluorescence (Trilogy, Turner Designs), cultures were maintained semi-continuously, diluting (up to $90 \%$ with fresh media) periodically to keep cells in the exponential phase for the duration of the experiment. For experimental treatments, cells from independent culture flasks (representing replicates) were gently filterconcentrated above $2 \mu \mathrm{m}$ polycarbonate membrane filters (Millipore) and resuspended into $250 \mathrm{ml}$ culture flasks. At each temperature treatment of -1.5 , +2 and $+5^{\circ} \mathrm{C}\left( \pm 0.3^{\circ} \mathrm{C}\right)$, cells were transferred into 4 salinities $-31,34,55$ and $70( \pm 0.5)$ - and were given $72 \mathrm{~h}$ in their new conditions before measurements were made. A $3 \mathrm{~d}$ acclimation period was chosen in order to investigate short-term acclimation strategies of 3 diatom species during a rapid freezing or thawing event. Salinities were adjusted either by the addition of MilliQ water or sodium chloride $(\mathrm{NaCl})$ salt (Sigma) and were confirmed by refractometer.

Chl a fluorescence. Fluorescence-based estimates of photosynthesis were measured using a Pulse Amplitude Modulated fluorometer (Water-PAM; Walz). A $3 \mathrm{ml}$ aliquot of each treatment was transferred into a quartz cuvette and maintained under continuous stirring to prevent settling. After 5 min of dark adaptation, minimum $\left(F_{0}\right)$ and maximum $\left(F_{\mathrm{m}}\right)$ fluorescence were obtained. This was followed by the sequential application of 9 actinic light levels (28, $42,65,100,150,320,680,1220$ and $2260 \mu \mathrm{mol}$ photons $\mathrm{m}^{-2} \mathrm{~s}^{-1}$ ) applied for $5 \mathrm{~min}$ each, with saturating pulses of light (pulse duration $=0.6 \mathrm{~s}$; pulse intensity $>3000 \mu \mathrm{mol}$ photons $\mathrm{m}^{-2} \mathrm{~s}^{-1}$ ) applied every minute. Relative electron transport rate (rETR) was calculated as the product of effective quantum yield $\left(\varphi_{\text {PSII }}\right)$ and irradiance ( $\mu \mathrm{mol}$ photons $\mathrm{m}^{-2} \mathrm{~s}^{-1}$ ) and normalised to chl a concentration ( $\mathrm{mg} \mathrm{l}^{-1}$ ).

Oxygen evolution. Oxygen uptake and evolution were measured using a 24 -well plate reader optode system (Pre Sens, Precision Sensing). Aliquots ( $3 \mathrm{ml}$ ) of filter-concentrated cultures (3-fold) were transferred into 36 wells of two 24 -well plates and left in the dark for 30 min while oxygen consumption was monitored. Cells were then incubated at 9 light levels $(20,40,65,100,160,300,600,1100$ and $2250 \mu \mathrm{mol}$ photons $\mathrm{m}^{-2} \mathrm{~s}^{-1}$ ) for $1 \mathrm{~h}$ (for each irradiance) and the oxygen evolution rate was determined. Light levels were attained by covering the well plate lids with neutral density filters and light was provided by a non-heat radiating light source (Zeiss KL2500). Oxy- 
gen flux measurements $\left(\mu m o l \mathrm{O}_{2} \mathrm{l}^{-1} \mathrm{~h}^{-1}\right.$ ) were used to calculate NPP rates at each light level and data were normalised to $\mathrm{chl} \mathrm{a}\left(\mathrm{mg} \mathrm{l}^{-1}\right)$ concentration. All fluorescence and oxygen measurements were conducted at each corresponding treatment temperature.

Chl a concentration. Chl a concentrations for fluorescence and oxygen measurements were determined by filtering $(10 \mathrm{ml})$ samples onto $25 \mathrm{~mm}$ Whatman GF/F filters, which were immediately frozen in liquid nitrogen and stored in the dark at $-80^{\circ} \mathrm{C}$ for later analysis. Pigments were extracted in $90 \%$ acetone and left in the dark at $4^{\circ} \mathrm{C}$ for $24 \mathrm{~h}$. Pigment concentrations were measured on a spectrophotometer (Cary 50) at wavelengths of 750, 664 and $630 \mathrm{~nm}$ and calculated according to Ritchie (2006).

Data analysis. Relative ETR (rETR) and oxygen evolution data were plotted according to the different temperature and salinity conditions experienced in the Antarctic; although not perfectly representative of the natural world, salinity and temperature treatments were combined to correspond to different Antarctic ecological niche environments: sea ice $\left(-1.5^{\circ} \mathrm{C}\right.$ at 70$)$, meltwater $\left(+2^{\circ} \mathrm{C}\right.$ at 31$)$ and pelagic $\left(+5^{\circ} \mathrm{C}\right.$ at 34$)$ (Fig. 1). Oxygen evolution and fluorescence data were fitted according to a double exponential function as in Ralph \& Gademann (2005). All photosynthetic parameters derived from the oxygen and fluorescence data, including maximum rate of oxygen evolution $\left(\mathrm{O}_{2 \max }\right)$, light utilisation efficiency $(\alpha)$, minimum saturating irradiances $\left(E_{\mathrm{K}}\right)$, optimal photosynthetic irradiance $\left(E_{\mathrm{M}}\right)$, photoinhibitory irradiance $\left(E_{\mathrm{B}}\right)$ and maximum electron transport rate $\left(E T R_{\max }\right)$, were obtained from these curves following Ralph \& Gademann (2005). The subscripts O2 and ETR are used to distinguish between the parameters derived from the oxygen data and those derived from the fluorescence measurements. Photosynthetic and NPP parameters were tested for statistical significance between species ( $F$. cylindrus, $P$. subcurvata and Chaetoceros sp.) and environments (sea ice, meltwater and pelagic) using a 2-factor ANOVA with Tukey's post hoc comparisons $(\alpha=0.05)$. All data were tested for homoscedasticity prior to analysis. The data for the photosynthetic parameters $\alpha_{\mathrm{O} 2}$ and $E_{\mathrm{KO} 2}$ were $\log$ transformed to meet the assumptions of ANOVA. Least-squares linear regression was used to determine the relationship between rETR and oxygen evolution rates for all data values below and above $E_{\mathrm{K}}$. To further investigate species-specific sensitivity to changes in temperature and salinity, photosynthetic parameters $\alpha_{\mathrm{O} 2}, \mathrm{E}_{\mathrm{KO} 2}$ and $\mathrm{O}_{2 \max }$ from oxy-
Table 1. Summary of data used to model seasonal daily solar irradiance in the winter sea ice, meltwater, pelagic and new sea ice environments for estimations of net primary production $\left(\mu \mathrm{mol} \mathrm{O}_{2}\right.$ $\mathrm{mg}^{-1} \mathrm{chl} \mathrm{a} \mathrm{d}{ }^{-1}$ ) for Fragilariopsis cylindrus, Pseudo-nitzschia subcurvata and Chaetoceros sp. Photoperiod values were obtained from www.esrl.noaa.gov/gmd/grad/solcalc for latitude $65^{\circ} \mathrm{S}$ and longitude $145^{\circ} \mathrm{E}$. Incident irradiance, $I_{0}$, values were derived from Lizotte \& Sullivan (1991). $k$, light attenuation coefficient

\begin{tabular}{|c|c|c|c|c|}
\hline Environmen & t Month & $\begin{array}{l}\text { Photoperioc } \\
\text { (h) }\end{array}$ & $\begin{array}{l}\text { d Maximum } I_{0} \\
\left(\mu \text { mol photons } \mathrm{m}^{-2} \mathrm{~s}^{-1}\right)\end{array}$ & $\begin{array}{c}k \\
\left(\mathrm{~m}^{-1}\right)\end{array}$ \\
\hline Sea ice & August & 8 & 150 & $1.5^{\mathrm{b}}$ \\
\hline Meltwater & November & 18.5 & 1500 & $0.09^{\mathrm{c}}$ \\
\hline Pelagic & January & 20 & $2000^{\mathrm{a}}$ & $0.03^{\mathrm{c}}$ \\
\hline New sea ice & March & 13 & 1800 & $1.5^{\mathrm{b}}$ \\
\hline $\begin{array}{l}{ }^{\mathrm{a}} \text { Estimated v } \\
{ }^{\mathrm{b}} \text { Taken from } \\
{ }^{\mathrm{c}} \text { Obtained fr. }\end{array}$ & $\begin{array}{l}\text { alue assumi } \\
\text { Maykut (19 } \\
\text { om Rasmus }\end{array}$ & $\begin{array}{l}\text { ing no clouc } \\
\text { 985) } \\
\text { et al. (2004 }\end{array}$ & d cover & \\
\hline
\end{tabular}

gen evolution data were plotted as a contour graph using the entire matrix of 4 salinities $(31,34,55$ and 70 ) and 3 temperatures $\left(-1.5,+2\right.$ and $\left.+5^{\circ} \mathrm{C}\right)$ that were tested.

NPP estimates. To place these results in a broader and more ecologically relevant context, the parameters derived from the light response curves were used to estimate daily integrated NPP $\left(\mu \mathrm{mol} \mathrm{O}_{2}\right.$ $\mathrm{mg}^{-1} \mathrm{chl} \mathrm{a} \mathrm{d}{ }^{-1}$ ) for each species under each environmental condition. Daily surface irradiance was computed as a bell-shaped curve with a noon maximum

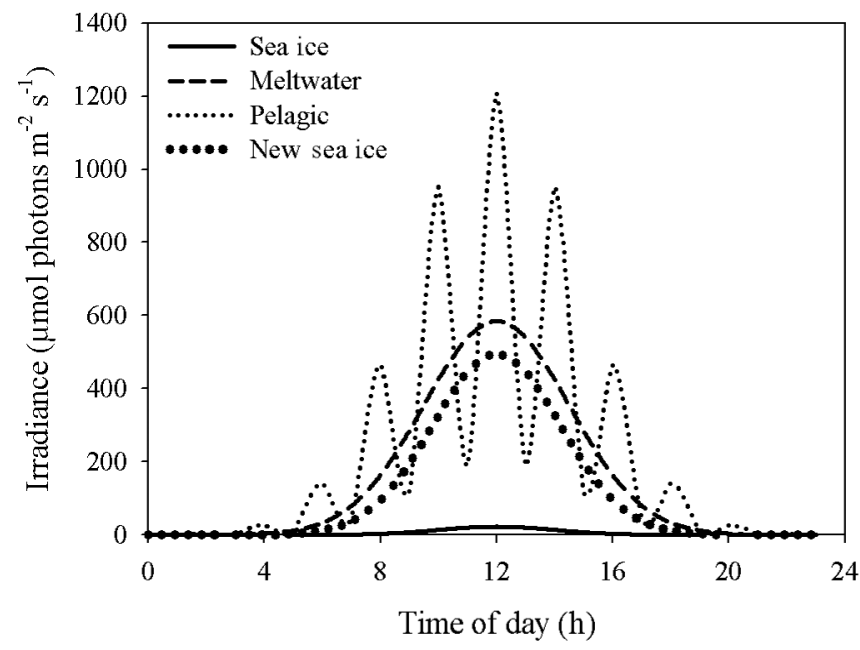

Fig. 2. Modelled daily in situ solar irradiance for microalgae in the sea ice (August, late winter), meltwater (November, spring), pelagic (January, summer) and new sea ice (March, autumn) environments at $65^{\circ} \mathrm{S}$ and $145^{\circ} \mathrm{E}$. Fluctuations in irradiance are shown by the $1: 1 \mathrm{~h}$ mixing pattern for photosynthetically active radiation at 15 and $60 \mathrm{~m}$ 
irradiance and a photoperiod typical of each environment derived from literature values (Table 1, Fig. 2). Data on the monthly photoperiod for each environmental condition were taken from www.esrl. noaa.gov/gmd/grad/solcalc, which are based on the astronomical algorithms of Jean Meeus (Earth System Research Laboratory, National Oceanic \& Atmospheric Administration) using the latitude $\left(65^{\circ} \mathrm{S}\right)$ and longitude $\left(145^{\circ} \mathrm{E}\right)$ of the east Antarctic seasonal sea ice zone south of the polar front. The photoperiods chosen were for the months of August, November, January and March to represent winter sea ice, spring meltwater, summer pelagic and autumn new ice conditions, respectively (Table 1). Approximations of maximum daily irradiance values for the different months were derived from the measurements of Lizotte \& Sullivan (1991) that were taken at a similar latitude (approx. $64^{\circ} \mathrm{S}$ ) (Table 1). Given missing data for January, summer maximum irradiance was estimated to be $2000 \mu \mathrm{mol}$ photons $\mathrm{m}^{-2} \mathrm{~s}^{-1}$ (Rozema et al. 2001) assuming no cloud cover. Irradiance within the water column or sea ice was estimated using Beer's Law:

$$
I_{z}=n I_{0} \mathrm{e}^{-k z}
$$

where $I_{z}$ is the irradiance at depth $z_{1} I_{0}$ is incident irradiance, $k$ is the light attenuation coefficient and $n$ is the transmissivity of the interface between air and water or air and ice. The attenuation coefficients differed between environments (Table 1). For the meltwater and pelagic environments, $k$-values were taken from Rasmus et al. (2004), who measured attenuation from the marginal ice zone to the polar front in the range of 0.03 to $0.09 \mathrm{~m}^{-1}$. The higher attenuation values were found at the ice edge and polar front because of increased phytoplankton biomass, with the lowest attenuation measured in intermediate pelagic waters (Rasmus et al. 2004). Therefore, $k$-values of 0.09 and $0.03 \mathrm{~m}^{-1}$ were used for the meltwater and pelagic environments, respectively (Table 1). For the sea ice environment, a $k$-value of $1.5 \mathrm{~m}^{-1}$ was used (Maykut 1985). To account for reflectance at the air-sea interface in the meltwater and pelagic environments, $n$ was assumed to be equal to 0.95 (Gregg \& Carder 1990; valid for solar zenith angles less than $45^{\circ}$ ). To account for irradiance loss due to high albedo of snow and ice, $n$ was set to 0.2 and 0.5 in the presence and absence of snow, respectively (Maykut 1985).

To better simulate fluctuating light conditions that result from strong vertical mixing, pelagic irradiance was determined at 2 depths $(15$ and $60 \mathrm{~m})$ and values obtained from each were used interchange- ably on a 1:1 h high:low light cycle for the entire photoperiod (Fig. 2). It is recognised that the irradiance values are only model estimates for in situ irradiance that use oversimplified coefficients of extinction and albedo, and that these modelled data fail to account for variations in absorption, reflection and scattering properties of snow, ice and water of differing composition.

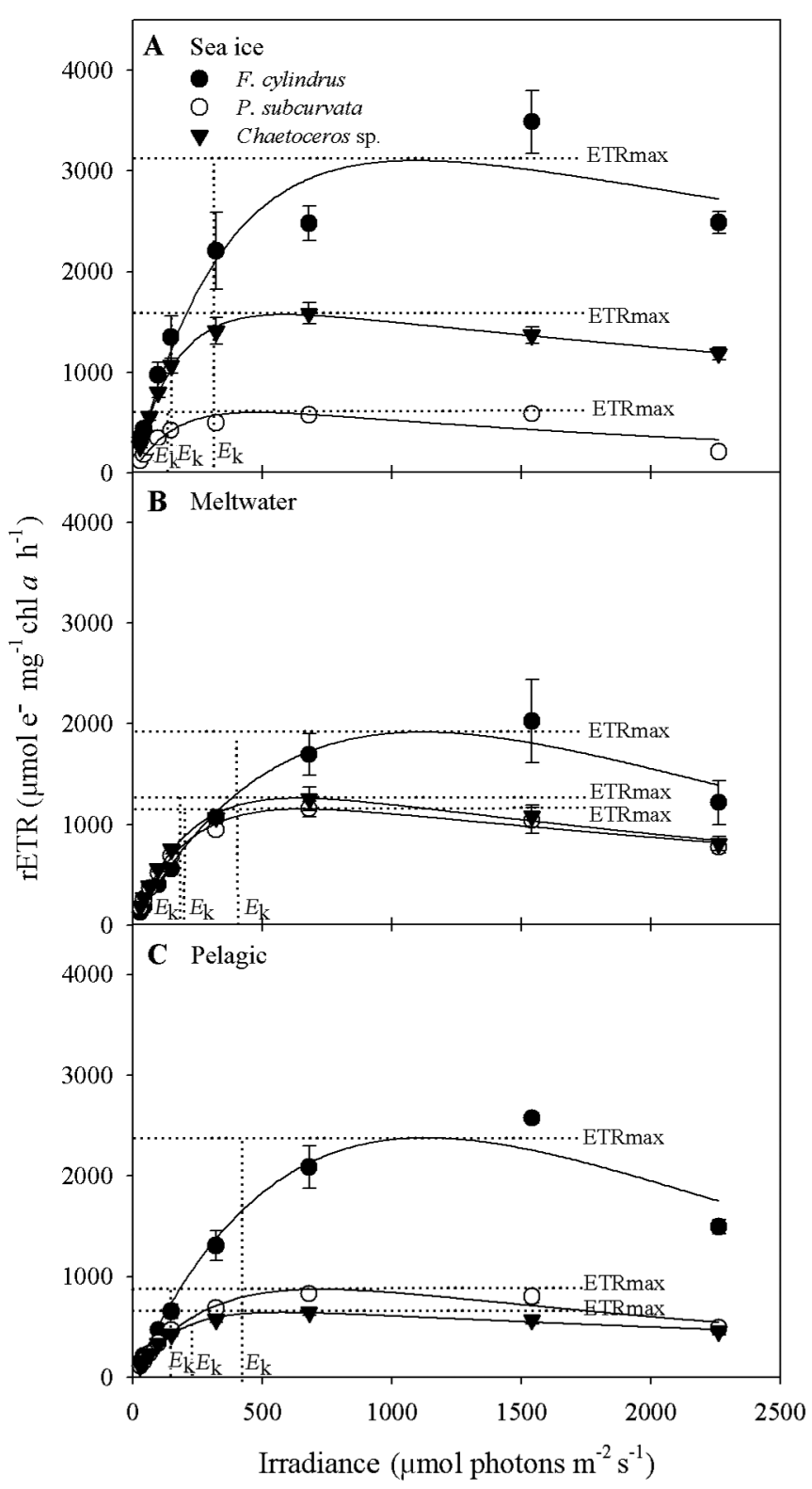

Fig. 3. Relative electron transport rates (rETR) as a function of irradiance in the Antarctic diatoms Fragilariopsis cylindrus, Pseudo-nitzschia subcurvata and Chaetoceros sp. under (A) sea ice, (B) meltwater and (C) pelagic conditions. Maximum electron transport rate $\left(\mathrm{ETR}_{\max }\right)$ and saturating irradiance $\left(E_{\mathrm{K}}\right)$ are shown (dotted lines). Data represent means $\pm \mathrm{SD}(\mathrm{n}=4)$ 
Table 2. Photosynthetic parameters: relative maximum electron transport rate $\left(\mathrm{rETR}_{\max }\right)$, maximum oxygen evolution $\left(\mathrm{O}_{2 \text { max }}\right)$, light utilisation efficiency $(\alpha)$ and minimum saturating irradiance $\left(E_{\mathrm{K}}\right)$ calculated from light response curves of rETR or oxygen evolution according to Ralph \& Gademann (2005). Data represent means \pm SD $(\mathrm{n}=4)$ for Fragilariopsis cylindrus, Pseudonitzschia subcurvata and Chaetoceros sp.

\begin{tabular}{|c|c|c|c|c|c|c|c|}
\hline \multirow{3}{*}{$\begin{array}{l}\text { Ecosystem } \\
\text { Sea ice }\end{array}$} & \multirow{3}{*}{$\begin{array}{l}\text { Species } \\
\text { F. cylindrus }\end{array}$} & \multicolumn{3}{|c|}{ — Light response curve of rETR } & \multicolumn{3}{|c|}{ — Light response curve of oxygen evolution - } \\
\hline & & 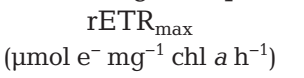 & \multicolumn{2}{|c|}{$\begin{array}{l}\alpha \underset{K}{E_{K}} \\
\quad\left(\mu \mathrm{mol} \text { photons } \mathrm{m}^{-2} \mathrm{~s}^{-1}\right)\end{array}$} & $\begin{array}{c}\mathrm{O}_{2 \max } \\
\left(\mu \mathrm{mol} \mathrm{O} \mathrm{mg}^{-1} \mathrm{chl} a \mathrm{~h}^{-1}\right)\end{array}$ & \multicolumn{2}{|c|}{$\alpha \quad \begin{array}{c}\alpha \quad E_{\mathrm{K}} \\
\\
\left(\mu \mathrm{mol} \text { photons } \mathrm{m}^{-2} \mathrm{~s}^{-1}\right)\end{array}$} \\
\hline & & $3105 \pm 403$ & $10.4 \pm 3.7$ & $315 \pm 81$ & $780 \pm 105$ & $12.8 \pm 3.9$ & $61 \pm 3.6$ \\
\hline & P. subcurvata & $603 \pm 76$ & $4.6 \pm 0.3$ & $132 \pm 24$ & $332 \pm 39.9$ & $5.1 \pm 0.7$ & $44 \pm 6.8$ \\
\hline & Chaetoceros sp. & p. $\quad 1577 \pm 241$ & $10.9 \pm 1.6$ & $144 \pm 17$ & $373 \pm 61.9$ & $10.0 \pm 2.5$ & $37 \pm 2.3$ \\
\hline \multirow[t]{3}{*}{ Meltwater } & F. cylindrus & $1929 \pm 526$ & $4.73 \pm 0.85$ & $406 \pm 66$ & $470 \pm 62$ & $5.22 \pm 1.3$ & $89 \pm 8.3$ \\
\hline & P. subcurvata & $1163 \pm 149$ & $6.38 \pm 0.55$ & $183 \pm 28$ & $449 \pm 133$ & $7.8 \pm 1.4$ & $57 \pm 6.5$ \\
\hline & Chaetoceros sp. & p. $1265 \pm 232$ & $7.07 \pm 0.31$ & $178 \pm 25$ & $276 \pm 90$ & $4.1 \pm 1.8$ & $68 \pm 11$ \\
\hline \multirow[t]{3}{*}{ Pelagic } & F. cylindrus & $2382 \pm 307$ & $5.70 \pm 1.20$ & $420 \pm 106$ & $1087 \pm 106$ & $6.07 \pm 0.43$ & $163 \pm 3.6$ \\
\hline & P. subcurvata & $877 \pm 79$ & $3.95 \pm 0.62$ & $225 \pm 35$ & $346 \pm 33$ & $4.8 \pm 1.7$ & $50 \pm 4$ \\
\hline & Chaetoceros sp. & $643 \pm 55$ & $4.44 \pm 0.53$ & $145 \pm 73$ & $270 \pm 36$ & $8.01 \pm 0.93$ & $56 \pm 15$ \\
\hline
\end{tabular}

\section{RESULTS}

\section{Chl a fluorescence}

Relative ETR varied between all 3 species and all environments (Fig. 3). There was more than a 2-fold difference in rETR for Fragilariopsis cylindrus under the pelagic and sea ice conditions when compared with the other 2 species (Fig. 3). Pseudo-nitzschia subcurvata showed minimal rETR under sea icelike conditions and maximal rates under the low saline (meltwater) conditions (Fig. 3A,B). In contrast, Chaetoceros sp. showed the reverse, with maximal rETR in the sea ice and minimal rates under pelagic conditions (Fig. 3A,C). Maximum rETR ( $\mathrm{rETR}_{\max }$ ) was significantly different between all 3 species across all 3 salinity and temperature treatments $(\mathrm{p}<0.001)$. It was consistently higher in F. cylindrus in all environments, with the highest values measured under the conditions similar to sea ice (Table 2). For P. subcurvata, values of $\mathrm{rETR}_{\max }$ were lowest under the sea ice conditions and highest in meltwater conditions (Table 2). A decreasing trend from sea ice to the pelagic environment was measured in Chaetoceros $\mathrm{sp}$. There were significant differences in light utilisation efficiency $\left(\alpha_{\mathrm{ETR}}\right)$ between environmental conditions $(\mathrm{p}=0.001)$ and between all 3 species $(\mathrm{p}<0.001)$, with the highest $\alpha_{\text {ETR }}$ measured in both F. cylindrus and Chaetoceros sp. acclimated to sea ice conditions (Table 2), whereas in P. subcurvata the highest value was measured under meltwater conditions (Table 2). Minimum saturating irradiances measured by fluorescence $\left(E_{\mathrm{KETR}}\right)$ varied significantly between species $(p<0.001)$ and across the 3 environments $(p=0.001)$.
In all 3 environments, $E_{\text {KETR }}$ was greatest in F. cylindrus, increasing from the sea ice to the pelagic environment. Minimum saturating irradiance levels were relatively similar in the other 2 species. There was an increasing trend from the sea ice to the pelagic environment for $P$. subcurvata, but no difference for Chaetoceros sp. between the 3 environments (Fig. 3, Table 2).

\section{Oxygen evolution}

The oxygen data showed very similar patterns to the rETR light response curves, with clear variations between all 3 species in all 3 environments (Fig. 4). Again, there was more than a 2-fold difference in NPP for Fragilariopsis cylindrus under the pelagic and sea ice conditions when compared with the other 2 species (Fig. 4). As with the fluorescence data, Pseudo-nitzschia subcurvata showed minimal NPP rates under sea ice conditions and maximal rates under meltwater conditions (Fig. 4A,B). In contrast, Chaetoceros sp. showed a decreasing trend in oxygen evolution rates from the sea ice to the pelagic environment (Fig. 4). Maximum oxygen evolution $\left(\mathrm{O}_{2 \max }\right)$ was significantly different between all 3 species across all 3 treatments $(\mathrm{p}<0.001)$ and was consistently higher in Fragilariopsis cylindrus under all environmental conditions (Table 2). There were significant differences in light utilisation efficiency $\left(\alpha_{\mathrm{O} 2}\right)$ between environmental conditions across the 3 species $(\mathrm{p}<0.001)$, with the highest $\alpha_{\mathrm{O}_{2}}$ measured in both $F$. cylindrus and Chaetoceros sp. acclimated to sea ice conditions (Table 2). As with the fluorescence data, the highest 


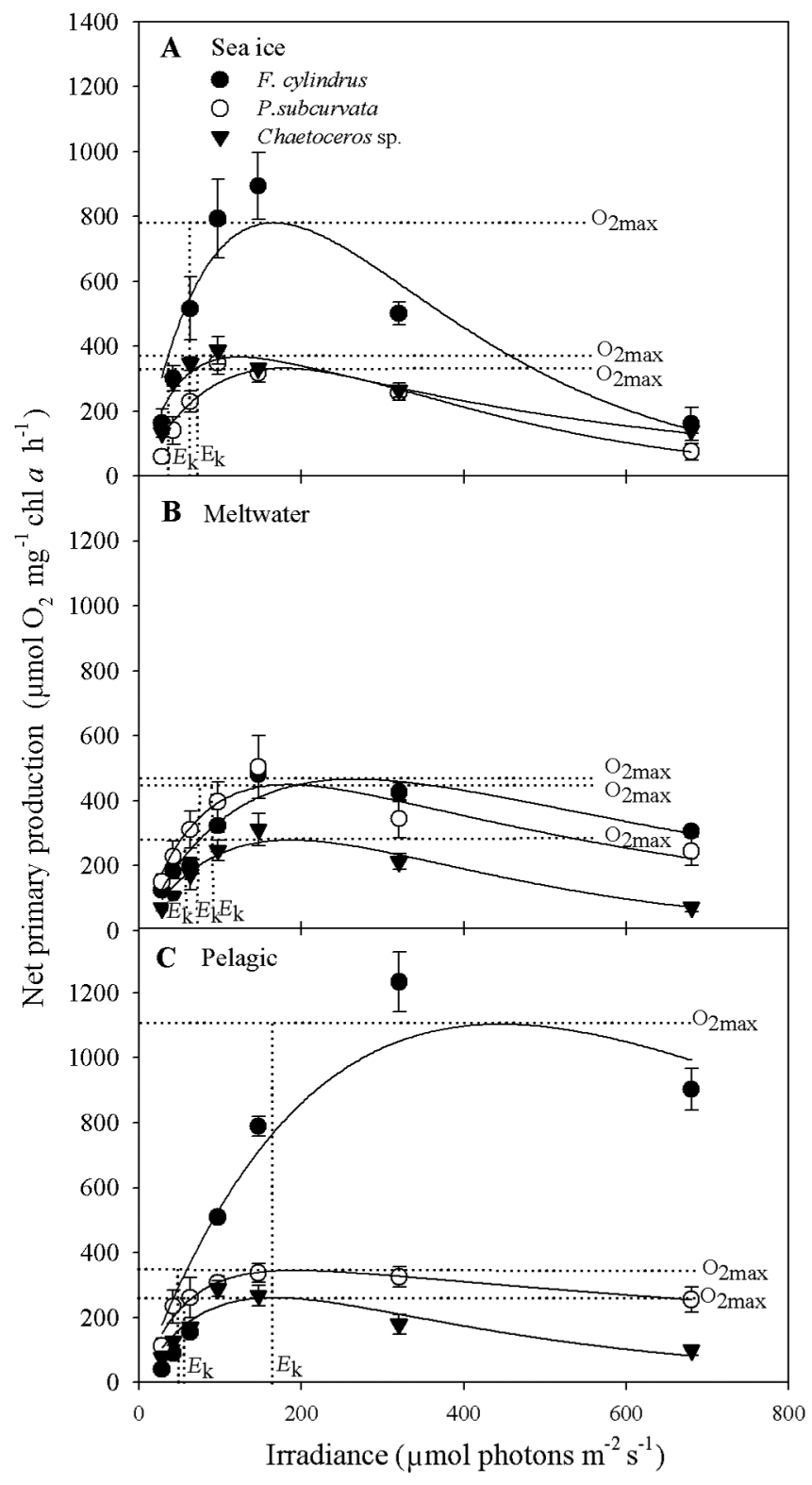

Fig. 4. Net primary production (measured as oxygen evolution) as a function of irradiance in the Antarctic diatoms Fragilariopsis cylindrus, Pseudo-nitzschia subcurvata and Chaetoceros sp. exposed to (A) sea ice, (B) meltwater and (C) pelagic conditions. Maximum oxygen evolution rates $\left(\mathrm{O}_{2 \text { max }}\right)$, and saturating irradiance $\left(E_{\mathrm{K}}\right)$ are shown (dotted lines). Data represent means $\pm \mathrm{SD}(\mathrm{n}=4)$

$\alpha_{\mathrm{O} 2}$ value was measured under meltwater conditions for Pseudo-nitzschia subcurvata (Table 2). Minimum saturating irradiances $\left(E_{\mathrm{KO} 2}\right)$ varied significantly between species across the 3 environments $(\mathrm{p}<0.001)$. In all 3 environments, $E_{\mathrm{KO} 2}$ was greatest in $F$. cylindrus and increased from the sea ice to the pelagic environment. In the other 2 species, $E_{\mathrm{KO} 2}$ was lowest under sea ice conditions and maximal in the meltwater environment (Fig. 4, Table 2).
Table 3. Photosynthetic parameters: optimal photosynthetic irradiance $\left(E_{\mathrm{M}}\right)$ and photoinhibitory irradiance $\left(E_{\mathrm{B}}\right)$ calculated from light response curves of oxygen evolution according to Ralph \& Gademann (2005). Data represent means $\pm \mathrm{SD}(\mathrm{n}=4)$ for Fragilariopsis cylindrus, Pseudo-nitzschia subcurvata and Chaetoceros sp.

\begin{tabular}{|llrc|}
\hline Environment & Species & $\begin{array}{c}E_{\mathrm{M}} \\
\left(\mu \mathrm{mol} \text { photons } \mathrm{m}^{-2} \mathrm{~s}^{-1}\right)\end{array}$ \\
\hline Sea ice & F. cylindrus & $124 \pm 10$ & $138 \pm 21$ \\
& P. subcurvata & $62 \pm 17$ & $155 \pm 35$ \\
& Chaetoceros sp. & $36 \pm 4.4$ & $403 \pm 192$ \\
Meltwater & F. cylindrus & $185 \pm 21$ & $969 \pm 77$ \\
& P. subcurvata & $64 \pm 38$ & $554 \pm 156$ \\
& Chaetoceros sp. & $132 \pm 31$ & $201 \pm 28$ \\
Pelagic & F. cylindrus & $366 \pm 9.8$ & $367 \pm 9.9$ \\
& P. subcurvata & $48 \pm 11$ & $1077 \pm 477$ \\
& Chaetoceros sp. & $86 \pm 38$ & $756 \pm 86$ \\
\hline
\end{tabular}

\section{Optimal irradiance and photoinhibition}

Optimal photosynthetic irradiance $\left(E_{\mathrm{MO} 2}\right)$ in Fragilariopsis cylindrus was approximately double the minimum saturating irradiance values under each environmental condition and, like $E_{\mathrm{KO} 2}$ (Table 2), increased from the sea ice to the pelagic environmental conditions (Table 3). In Pseudo-nitzschia subcurvata there was no difference in $E_{\mathrm{MO} 2}$ between environmental conditions, whereas for Chaetoceros sp., optimal irradiance was greatest under meltwater and lowest under sea ice conditions (Table 3). Photoinhibitory irradiance $\left(E_{\mathrm{BO} 2}\right)$ revealed photoinhibition in all species under all environmental conditions (Fig. 4, Table 3). The greatest photoinhibition was measured in the meltwater and lowest under sea ice conditions for $F$. cylindrus. It increased from the sea ice to the pelagic environment in P. subcurvata and was lowest under meltwater conditions for Chaetoceros sp. (Table 3).

\section{Oxygen- versus fluorescence-based NPP}

Oxygen evolution and rETR plotted together as a function of light showed good correlation at irradiances below $E_{\mathrm{K}}$, but considerable differences in shape of the curve at higher irradiances (Fig. 5). The pooled oxygen and fluorescence data for all species under all environmental conditions showed a significant correlation between the linear component of the fluorescence and oxygen data $\left(\mathrm{R}^{2}=0.8392, \mathrm{p}=\right.$ 0.0001; Fig. 6, regression A). However, the remaining 


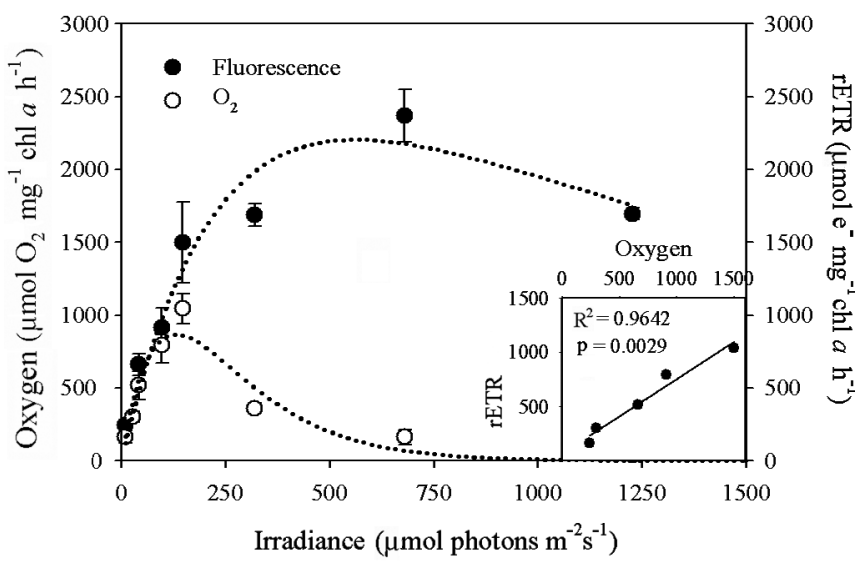

Fig. 5. Comparison of light response curves for oxygen and fluorescence-based photosynthesis in Fragilariopsis cylindrus under sea-ice conditions. Light curves were fitted according to Ralph \& Gademann (2005). The relationship between relative electron transport rates (rETR) and $\mathrm{O}_{2}$ evolution at low irradiance (initial points of light curve) are fitted with a linear regression (inset). Data represent means $\pm \mathrm{SD}(\mathrm{n}=4)$

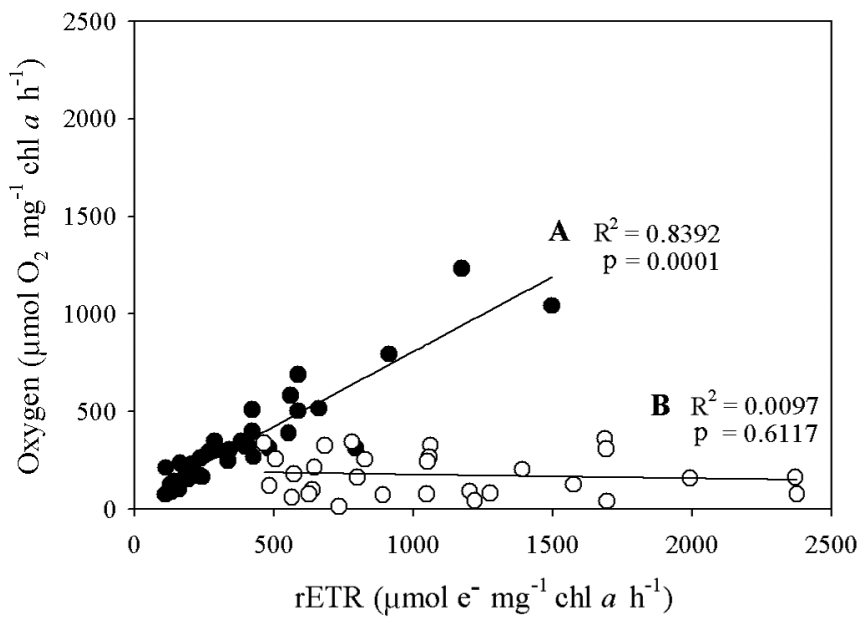

Fig. 6. Correlation between pooled means of oxygen- and fluorescence-based photosynthesis of the values in the light curve below $E_{\mathrm{K}}$ (black circles, $\mathrm{A}$ ) and the remaining points above saturating irradiance $\left(E_{\mathrm{K}}\right.$ white circles, B) after which the oxygen and fluorescence deviate. Data are fitted with a linear regression. Data represent means of all species under sea ice, meltwater and pelagic conditions $(n=4)$

data for irradiance levels well above $E_{\mathrm{K}}$ for each species was not significant (Fig. 6, regression B).

\section{Salinity and temperature responses}

The complete matrix of photosynthetic parameters determined from the oxygen data, $\alpha_{\mathrm{O} 2}, \mathrm{O}_{2 \max }$, and
$E_{\mathrm{KO} 2}$ in response to changes in salinity and temperature, revealed differences between the 3 diatom species (Fig. 7). Fragilariopsis cylindrus and Chaetoceros sp. showed high light utilisation efficiency $\left(\alpha_{\mathrm{O} 2}\right)$ in the low to mid-range temperatures and mid to high salinities (Fig. 7A,C), whereas Psuedonitzschia subcurvata showed a preference for the intermediate to high temperatures and lower salinities (Fig. 7B). Maximum photosynthesis $\left(\mathrm{O}_{2 \max }\right)$ varied across the 3 species, with $F$. cylindrus yielding maximum values at mid to high salinities and warmer temperatures (Fig. 7D). F. cylindrus showed a salinity threshold in which high rates of photosynthesis began to decline unless temperature also decreased (Fig. 7D). In P. subcurvata, photosynthetic activity $\left(\mathrm{O}_{2 \max }\right)$ was optimal at lower salinities and warmer conditions (Fig. 7E); for Chaetoceros sp., maximum photosynthesis occurred at higher salinities and mid-range temperatures (Fig. 7F). Minimum light saturation values $\left(E_{\mathrm{KO} 2}\right)$ were highest in warmer temperatures for all 3 species; however, there were some differences in salinity sensitivity between species. F. cylindrus showed high values across a range of salinities (Fig. $7 \mathrm{G}$ ); in $P$. subcurvata the lowest salinities yielded the highest saturating irradiances (Fig. 7H). Chaetoceros sp. showed higher minimum light saturation values at the higher salinities (Fig. 7I).

\section{Estimated daily NPP: species, environment and light climate}

Daily estimates of integrated NPP determined from the modelled integrated PAR for each environment (Fig. 2) showed Fragilariopsis cylindrus with the highest productivity of all 3 species under all environments (Fig. 8). F. cylindrus showed a light-dependent response, with low values in the winter sea ice and very high values in the meltwater, pelagic and newly formed ice environments (Fig. 8). NPP was strongly inhibited in Pseudonitzschia subcurvata under sea ice conditions at both high and low irradiances; however, rates of NPP were highest under the higher irradiances combined with lower salinities and warmer temperatures of the meltwater and pelagic environments (Fig. 8). Daily estimates of NPP for Chaetoceros sp. were much lower in the meltwater environment compared with the other 2 species, but followed the same light-dependent pattern as $F$. cylindrus, with the highest rates estimated for the pelagic environment (Fig. 8). 
A

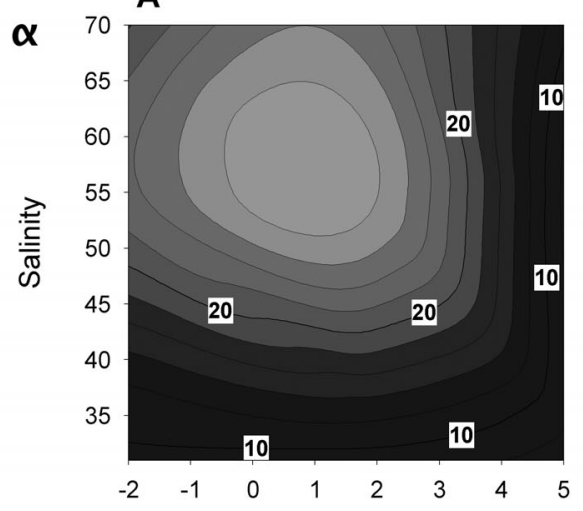

D

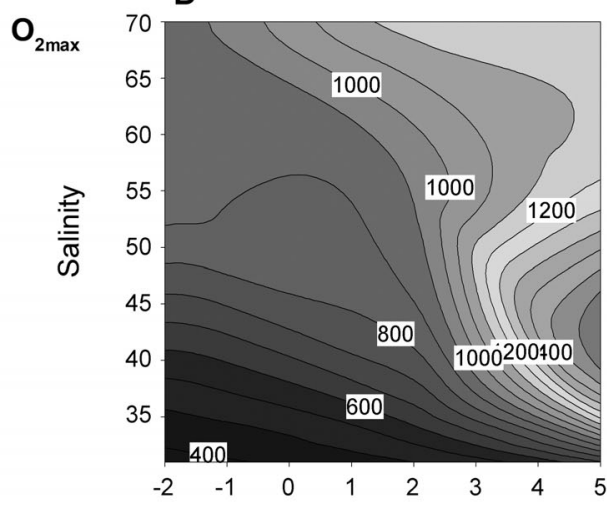

G

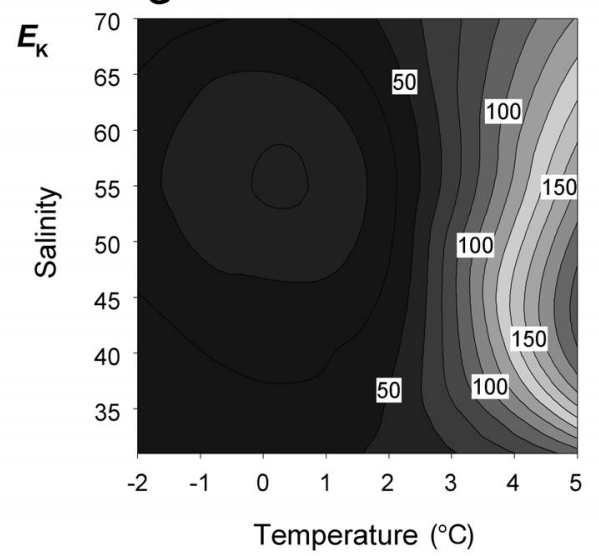

P. subcurvata

B

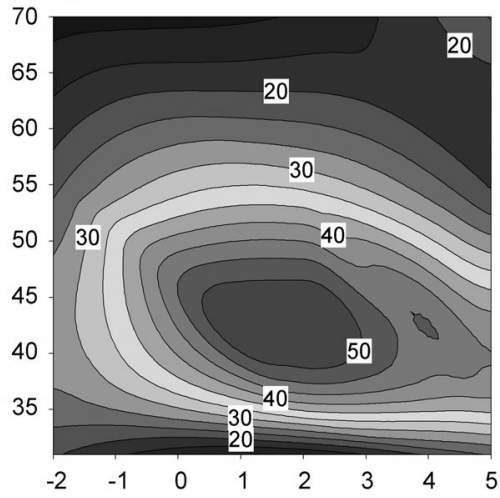

E

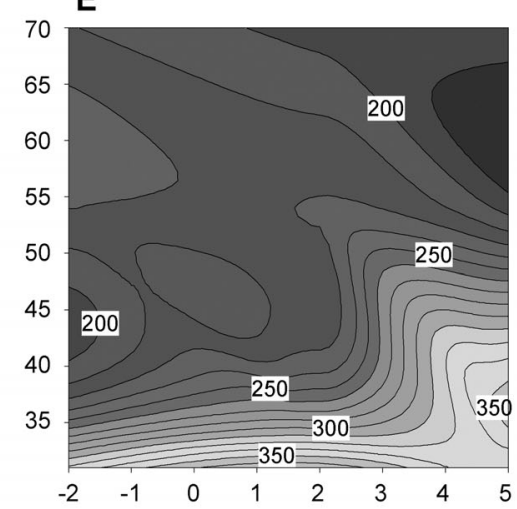

H

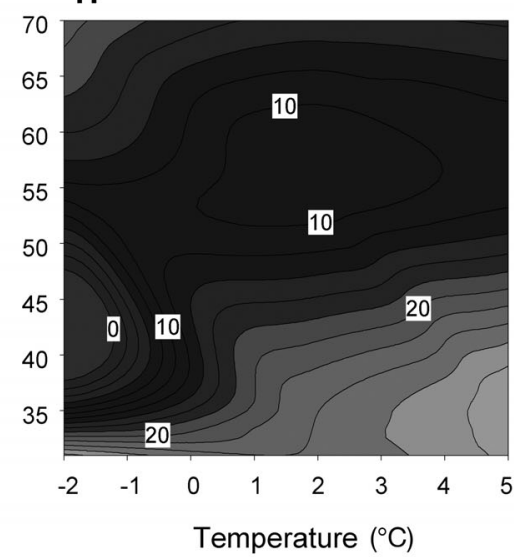

Chaetoceros sp.
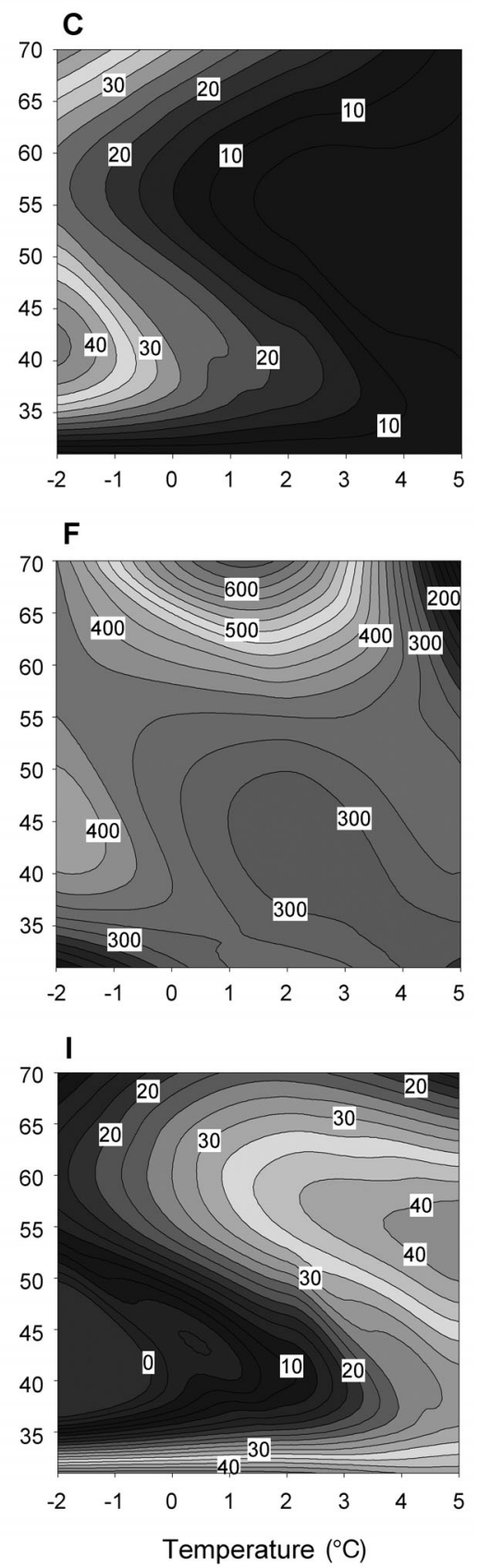

Fig. 7. Contour plots of the oxygen-derived parameters light utilisation efficiency $(\alpha)$, maximum oxygen evolution $\left(\mathrm{O}_{2 \mathrm{max}} \mu \mathrm{\mu mol}\right.$ $\left.\mathrm{O}_{2} \mathrm{mg}^{-1} \mathrm{chl} \mathrm{a} \mathrm{h}^{-1}\right)$ and minimum saturation irradiance $\left(E_{\mathrm{K} i} \mu \mathrm{mol}\right.$ photons $\left.\mathrm{m}^{-2} \mathrm{~s}^{-1}\right)$ in $(\mathrm{A}, \mathrm{D}, \mathrm{G})$ Fragilariopsis cylindrus, $(\mathrm{B}, \mathrm{E}, \mathrm{H})$

Pseudo-nitzschia subcurvata and (C, F, I) Chaetoceros sp. exposed to salinities of 31, 34, 55 and 70 at $-1.5,+2$ and $+5^{\circ} \mathrm{C}$

\section{DISCUSSION}

Microalgae exposed to variable environments generally possess the capacity for rapid acclimation and a highly plastic photosynthetic apparatus (Kolber et al. 1988). All 3 species of Antarctic diatoms exhibited photophysiological plasticity by their ability to accli- mate to the rapid shift in environmental condition. Each diatom showed different physiological responses that correlated well with their known distribution, displaying physiological preferences for one particular niche environment over another. The photosynthetic parameters obtained from the oxygen measurements showed similarity in the patterns to 


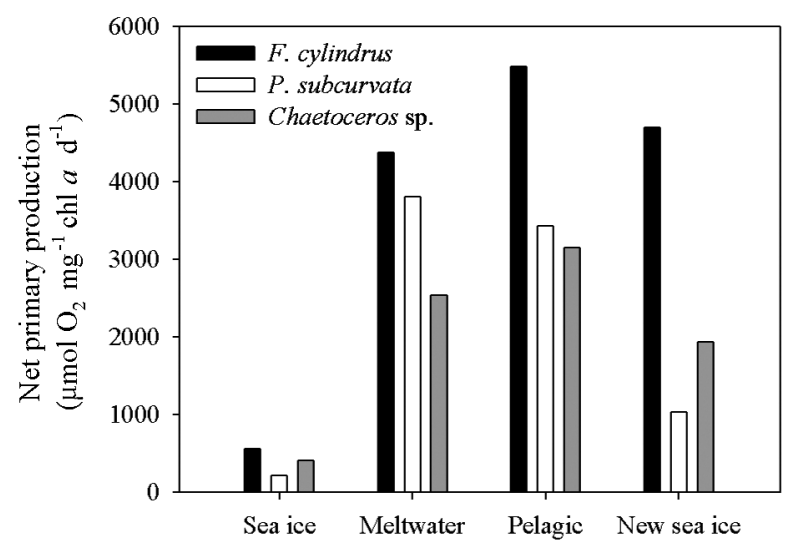

Fig. 8. Daily integrated net primary production as a function of modelled seasonal light climate (see Fig. 2) in the sea ice (late winter), meltwater (spring), pelagic (summer) and new sea ice (autumn) environments for Antarctic diatoms Fragilariopsis cylindrus, Pseudo-nitzschia subcurvata and Chaetoceros sp. exposed to altered salinity and temperature

those obtained from the fluorescence data (Table 2). However, there were some differences between the fluorescence and oxygen measurements including maximum photosynthesis in Fragilariopsis cylindrus (Table 2). According to oxygen measurements, $\mathrm{O}_{2 \max }$ occurred under pelagic conditions, yet rETR $_{\max }$, based on fluorescence data, occurred under sea ice conditions, which could be due to the presence of alternative electron cycling.

The variability in accessory pigments and physiological properties between species means that there is considerable heterogeneity in light utilisation efficiency within a phytoplankton community (Wilhelm 1990). The higher rates of light utilisation efficiency $(\alpha)$ in Fragilariopsis cylindrus and Chaetoceros sp. under sea ice conditions suggest an increase in light capturing capacity by the antenna of PSII, which would explain light saturation occurring at lower irradiances in these 2 species. In contrast, the small $\alpha$ under sea ice conditions measured in Pseudonitzschia subcurvata suggests a smaller PSII antenna, and explains the high irradiance required to reach photosynthetic saturation compared with the other environmental conditions (Juneau \& Harrison 2005). The lower $\alpha$-values measured in P. subcurvata under all 3 environmental conditions is likely because it is a much larger cell (approx. $50 \mu \mathrm{m}$ vs. $5 \mu \mathrm{m}$ ) and therefore has a much higher chl a content, leading to increased packaging effect and lower photoprotective capacity (Dimier et al. 2009). This suggests that this species would display maximum efficiency under stable light climates, such as those provided by the meltwater environment (Dierssen et al. 2002), which was indeed observed in this study.

Values of $E_{\mathrm{KO} 2}$, ranging between 37 and $163 \mu \mathrm{mol}$ photons $\mathrm{m}^{-2} \mathrm{~s}^{-1}$, are consistent with values measured from Antarctic phytoplankton both from the pack ice (Lizotte \& Sullivan 1991, Dower et al. 1996) and pelagic environments (Tilzer et al. 1986, Brightman \& Smith 1989). Saturating irradiance is an indicator of photoadaptation, changing as a result of light history and thereby helping to identify shade- vs. lightadapted species. The increase in $E_{\mathrm{K}}$ from the sea ice to the open ocean in Fragilariopsis cylindrus suggests that this species is well-adapted to sea ice conditions in which light levels are rarely as high in comparison to the meltwater or pelagic environments (Palmisano et al. 1987). By maximising light utilisation efficiency and not light absorption capacity-because light levels are rarely excessive- $F$. cylindrus can optimise photosynthesis in the sea ice environment. Additionally, F. cylindrus is well-adapted to the other environments, and by reducing light captured by the PSII antenna, the photosystem can tolerate higher irradiances such as the levels occurring in the meltwater and pelagic environments. Light saturation did not vary greatly between environments for Pseudonitzschia subcurvata, but was greatest in the meltwater environment. A higher $E_{\mathrm{K}}$ at lower salinities is indicative of a reduced capacity for low light acclimation (Arrigo \& Sullivan 1992), which makes sense for $P$. subcurvata given the reduced light utilisation efficiency observed. Similarly, both oxygen and fluorescence data revealed that Chaetoceros sp. exhibited the highest light saturation under meltwater conditions and not pelagic conditions, as was found in $F$. cylindrus. The seemingly contradictory higher $\mathrm{O}_{2}$ evolution $\left(\mathrm{O}_{2 \max }\right)$ under sea ice conditions may be the result of greater light respiration at the warmer temperatures. Previous work on another Antarctic Chaetoceros sp. showed that lower temperatures $\left(-1.5^{\circ} \mathrm{C}\right)$ resulted in more efficient carbon assimilation and less respiratory losses (Thomas et al. 1992). Although Chaetoceros sp. showed a light utilisation efficiency $(\alpha)$ under sea ice conditions that was similar to $F$. cylindrus, $E_{\mathrm{K}}$ was much lower, suggesting greater sensitivity to sea ice conditions and different light harvesting capacity.

The trends in $E_{K}$ were the same in the fluorescence and oxygen measurements, but there were large differences in the actual values, where $E_{\mathrm{K}}$ values determined from rETR were much higher than those obtained from the oxygen measurements (Fig. 4, Table 2). Such differences have been measured, with PSII $E_{\mathrm{K}}$ values determined by ETR exceeding values 
determined by oxygen evolution rates (Prasil et al. 1996, Gilbert et al. 2000, Wagner et al. 2006). This is due to the fact that oxygen evolution measures net photosynthesis, whereas fluorescence-based rETR represents gross PSII-dependent electron transport, failing to differentiate between electrons derived from water-splitting and electrons being re-cycled through PSII (Genty et al. 1989). Although no direct measurements of cyclic electron transport of PSII were made in this study, it seems highly likely that the difference in the shape of the light response curves and $E_{\mathrm{K}}$ values based on fluorescence and oxygen measurements can be attributed to the non-oxygen-consuming process of cyclic electron transport around PSII (Prasil et al. 1996, Lavaud et al. 2002). The advantage to cyclic electron transport is that it can be switched on faster than heat dissipation via non-photochemical quenching (Onno Feikema et al. 2006) and allows the cell to maintain maximum photosynthetic capacity while keeping energy-dependent quenching minimal (Lavaud 2007).

Relative ETR and $\alpha$ are temperature-dependent processes (Palmisano et al. 1987, Arrigo \& Sullivan 1992); however, only Chaetoceros sp. expressed such a response in this study (Table 2). Instead, a salinity trend was detected. Using the ${ }^{14} \mathrm{C}$ method, Arrigo \& Sullivan (1992) found rETR and $\alpha$ parameters to increase with increasing salinity up to 50 before declining again in Antarctic sea ice algal populations. A similar salinity trend was detected in this study, where rETR and $\alpha$ were highest in the sea ice and lowest in the meltwater environments for Fragilariopsis cylindrus (Table 2). This same trend was observed in $\alpha$, determined from the oxygen data, in Chaetoceros sp. (Table 2). However, for Pseudo-nitzschia subcurvata, maximum values of all parameters were detected under meltwater conditions, further implying adaptation to lower salinities. This response correlates well with a previous study where increased salinity retarded growth more than lowered temperatures (Aletsee \& Jahnke 1992), assuming photosynthetic activity as a proxy for growth.

Phytoplankton photosynthetic efficiency is influenced by both temperature and salinity, as both factors affect rates of photosynthesis. Factors can act independently (one has an effect, whereas the other does not), synergistically (the combined affect is greater than the individual) or antagonistically (where one stress offsets the damage of the other). Interactive effects between temperature and salinity were detected in Fragilariopsis cylindrus, where elevated salinity mitigated the effects of lower tempera- tures (Fig. 7). This demonstrates a situation in which multiple stressors, rather than causing a synergistic effect, can actually be less stressful than the individual stress. These data suggest that this mitigative response in $F$. cylindrus is linked with a greater adaptability to the sea ice environment (which naturally has simultaneously low temperatures and high salinities), supporting the observed dominance of this species in the Antarctic sea ice. In contrast, the same combination of low temperature and high salinity yielded low $\alpha_{\mathrm{O} 2}, \mathrm{O}_{2 \max }$ and $E_{\mathrm{KO} 2}$ values in Psuedonitzschia subcurvata, having more of a negative effect. At low salinities and warmer temperatures, $P$. subcurvata showed less photosynthetic stress, indicating temperature and salinity sensitivity and suggesting that its preferred ecological niche is somewhere between meltwater and pelagic conditions (Fig. 7). Chaetoceros sp. responded in a similar manner as $F$. cylindrus, but showed greater sensitivity towards low salinities, a situation in which an individual factor is responsible for negative responses alone.

It should be noted that this study compared acclimation capacity after only $3 d_{\text {i }}$ therefore, we cannot rule out the possibility that all species could in fact acclimate successfully to all conditions given more time. However, what this study does highlight is that there are species-specific differences in rapid acclimation capacity, which could have implications for an ecological competitive advantage. In addition, it must be noted that the short-term $(72 \mathrm{~h})$ acclimation period used in this study may have led to the experimental conditions slightly overestimating the stress of the sea ice environment, as the shift from growth environment $\left(+4^{\circ} \mathrm{C}\right.$ at a salinity of 34$)$ to the lowtemperature and high-salinity sea ice conditions $\left(-1.5^{\circ} \mathrm{C}\right.$ at 70$)$ would likely take longer to reach acclimation than to the meltwater conditions $\left(+2^{\circ} \mathrm{C}\right.$ at 32$)$. However, this would not have affected differences in the short-term acclimation capacity between the 3 species.

Daily integrated NPP was greatest in the summer pelagic environment and lowest under the winter sea ice conditions for Fragilariopsis cylindrus and Chaetoceros sp., whereas maximal NPP was calculated for Pseudo-nitzschia subcurvata under meltwater conditions (Fig. 8). The light-dependent response of $F$. cylindrus and Chaetoceros sp. highlights the strong link between light availability and NPP. For these 2 species, low irradiances limited the amount of active photosynthesis. In contrast, $P$. subcurvata showed an interactive effect of salinity and temperature with light, where the low temperature and high salinities 
of the sea ice environments drastically reduced NPP regardless of available irradiance. It is important to note that the growth irradiance in this experiment was not representative of field conditions and was instead kept constant throughout the salinity and temperature manipulations, potentially influencing the photoacclimation potential of the phytoplankton. Furthermore, the irradiance level used was below light saturation for photosynthesis in all species under all environmental conditions. Thus, it is possible that when acclimated to different light intensities, the diatoms may show entirely different photosynthesis versus irradiance characteristics, particularly with respect to photochemical efficiency at low irradiances and photoinhibition at higher light levels. Future studies should aim to combine light, temperature and salinity shifts to provide greater insight into the true photoacclimation potential and NPP of each species. Photoinhibition was not great enough to affect the light-dependent response of NPP in this study, but this could be an artefact of the constant photon fluence rates used. The greatest average daily irradiance of $232 \mu \mathrm{mol}$ photons $\mathrm{m}^{-2} \mathrm{~s}^{-1}$ in the pelagic environment resulted in the highest NPP regardless of high photoinhibition, with the exception of $P$. subcurvata, where salinity concentrations and constant high light had a greater influence over NPP (Fig. 8). Even with the fluctuations in light, the total irradiance was still greater than in the meltwater environment. Photoinhibition was present under all conditions with the exception of the winter sea ice scenario, which had a calculated daily mean irradiance of just $3.4 \mu \mathrm{mol}$ photons $\mathrm{m}^{-2} \mathrm{~s}^{-1}$. Therefore, the contribution of photoinhibition can be entirely ignored in the winter sea ice scenario. However, the low NPP values for P. subcurvata in both autumn and early spring sea ice environments is indicative of sensitivity to the high salinity and low temperatures, but also shows high light adaptation and limited photosynthetic plasticity for low light conditions. The higher NPP values of $P$. subcurvata compared with Chaetoceros sp. in the high light meltwater conditions is largely due to higher photoinhibition in Chaetoceros sp., whereas values are relatively similar in the pelagic waters as a result of the intermittent low light that drastically lowers NPP in P. subcurvata.

Although there are many recognised limitations to these modelled data, the derived values of NPP are consistent with the fluorescence and oxygen physiological data and all tell a similar story. Fragilariopsis cylindrus possesses a highly plastic photosystem and, although well-adapted for the sea ice environment, remains the most productive species under all 3 con- ditions. Based on this study, the results show that $F$. cylindrus is able to acclimate to the new salinity and temperature conditions more rapidly than the other 2 species, potentially giving it a competitive advantage in the marine environment. This strongly supports its wide distribution as a generalist species and its prevalence throughout the Antarctic marine ecosystem (Lizotte 2001, Kopczynska et al. 2007, Roberts et al. 2007, Beans et al. 2008). In contrast, Pseudonitzschia subcurvata showed a particular adaptation to meltwater characteristics, with a much lower level of photosynthetic plasticity for changes in salinity, temperature and light, perfectly matching the geographical environment where the species is known to be most abundant (Almandoz et al. 2008). Finally, Chaetoceros sp. exhibited an ability to adjust to sea ice conditions, but displayed a clear preference towards the more pelagic environment with sensitivity to low saline conditions, correlating with its known distribution in the Antarctic coastal pelagic environment.

\section{CONCLUSIONS}

Knowledge of species-specific photosynthetic capacity is essential to obtain good estimates of primary productivity (Juneau \& Harrison 2005). This study has shown that photosynthesis in 3 Antarctic diatoms is sensitive to rapid changes in temperature and salinity that occur in the Antarctic ecosystem during an annual cycle. Better understanding the influence these changes can have on photosynthesis and NPP may shed some light on the physiological mechanism(s) controlling the distribution of phytoplankton in the Antarctic marine environment. The speciesspecific sensitivities to changes in salinity and temperature uncovered in this study have strengthened the link between phytoplankton photosynthetic capacity and ecological niche occupancy.

Acknowledgements. Thanks to the 3 anonymous reviewers for their input to improve this paper. Thanks to Olivia Sackett for experimental assistance and Dr Isabel Jimenez-Denness for her support, helpful discussions and guidance. We are grateful to Dr A. Pankowski, Dr P. Assmy and Dr C. Hassler for supplying the 3 Antarctic cultures (F. Cylindrus, $P$. subcurvata and Chaetoceros sp., respectively). Financial support was provided by the Australian Research Council grant (DP0773558) awarded to P.J.R., Aquatic Processes Group and Department of Environmental Sciences, University of Technology, Sydney. K.P. was supported by an Australian Postgraduate Award and the Commonwealth Scientific and Industrial Research Organisation (CSIRO) top-up scholarship. 


\section{LITERATURE CITED}

Aletsee L, Jahnke J (1992) Growth and productivity of the psychrophilic marine diatoms Thalassiosira antarctica Comber and Nitzschiafriqida Grunow in batch cultures at temperatures below the freezing point of sea water. Polar Biol 11:643-647

> Almandoz GO, Ferreyra GA, Schloss IR, Dogliotti AI and others (2008) Distribution and ecology of Pseudonitzschia species (Bacillariophyceae) in surface waters of the Weddell Sea (Antarctica). Polar Biol 31:429-442

> Arrigo K, Sullivan CW (1992) The influence of salinity and temperature covariation on the photophysiological characteristics of Antarctic sea ice microalgae. J Phycol 28: 746-756

Bailey S, Melis A, Mackey KR, Cardol P and others (2008) Alternative photosynthetic electron flow to oxygen in marine Synechococcus. Biochim Biophys Acta 1777: 269-276

> Beans C, Hecq JH, Koubbi P, Vallet C, Wright S, Goffart A (2008) A study of the diatom-dominated microplankton summer assemblages in coastal waters from Terre Adélie to the Mertz Glacier, East Antarctica $\left(139^{\circ} \mathrm{E}-145^{\circ} \mathrm{E}\right)$. Polar Biol 31:1101-1117

Bendall DS, Manasse RS (1995) Cyclic photophosphorylation and electron transport. Biochim Biophys Acta 1229: 23-38

> Brightman RI, Smith WO Jr (1989) Photosynthesis-irradiance relationships of Antarctic phytoplankton during austral winter. Mar Ecol Prog Ser 53:143-151

> Dierssen HM, Smith RC, Vernet M (2002) Glacial meltwater dynamics in coastal waters west of the Antarctic peninsula. Proc Natl Acad Sci USA 99:1790-1795

Dimier C, Corato F, Tramontano F, Brunet C (2007) Photoprotection and xanthophyll-cycle activity in three marine diatoms. J Phycol 43:937-947

> Dimier C, Giovanni S, Ferdinando T, Brunet C (2009) Comparative ecophysiology of the xanthophyll cycle in six marine phytoplanktonic species. Protist 160:397-411

Dower KM, Lucas MI, Phillips R, Dieckmann G, Robinson DH (1996) Phytoplankton biomass, P-I relationships and primary production in the Weddell Sea, Antarctica, during the austral autumn. Polar Biol 16:41-52

Eicken H (1992) The role of sea ice in structuring Antarctic ecosystems. Polar Biol 12:3-13

> Geel C, Versluis W, Snel JFH (1997) Estimation of oxygen evolution by marine phytoplankton from measurement of the efficiency of Photosystem II electron flow. Photosynth Res 51:61-70

Genty B, Briantais JM, Baker NR (1989) The relationship between the quantum yield of photosynthetic electron transport and quenching of chlorophyll fluorescence. Biochim Biophys Acta 990:87-92

Gilbert M, Domin A, Becker A, Wilhelm C (2000) Estimation of primary productivity by chlorophyll $a$ in vivo fluorescence in freshwater phytoplankton. Photosynthetica 38: $111-126$

> Gleitz M, Thomas DN (1992) Physiological responses of a small Antarctic diatom (Chaetoceros sp.) to simulated environmental constraints associated with sea-ice formation. Mar Ecol Prog Ser 88:271-278

Gregg WW, Carder KL (1990) A simple spectral solar irradiance model for cloudless maritime atmospheres. Limnol Oceanogr 35:1657-1675

Guillard RR, Ryther JH (1962) Studies of marine planktonic diatoms I. Cyclotella nana Hudstedt and Detonula confervacea Cleve. Can J Microbiol 8:229-239

Juneau P, Harrison P (2005) Comparison by PAM fluorometry of photosynthetic activity of nine marine phytoplankton grown under identical conditions. Photochem Photobiol 81:649-653

> Kashino Y, Kudoh S, Hayashi Y, Suzuki Y and others (2002) Strategies of phytoplankton to perform effective photosynthesis in the North Water. Deep-Sea Res Part II 49: 5049-5061

Kolber Z, Zehr J, Falkowski P (1988) Effects of growth irradiance and nitrogen limitation on photosynthetic energy conversion in photosystem II. Plant Physiol 88:923-929

Kopczynska EE, Savoye N, Dehairs F, Cardinal D, Elskens M (2007) Spring phytoplankton assemblages in the Southern Ocean between Australia and Antarctica. Polar Biol 31:77-88

> Krause GH, Weis E (1991) Chlorophyll fluorescence and photosynthesis: the basics. Annu Rev Plant Physiol Plant Mol Biol 42:313-349

Lavaud J (2007) Fast regulation of phtosynthesis in diatoms: mechanisms, evolution and ecophysiology. Funt Plant Sci Biotechnol 1:267-287

> Lavaud J, van Gorkom H, Etienne AL (2002) Photosystem II electron transfer cycle and chlororespiration in planktonic diatoms. Photosynth Res 74:51-59

> Lavaud J, Strzepek RF, Kroth PG (2007) Photoprotection capacity differs among diatoms: possible consequences on the spatial distribution of diatoms related to fluctuations in the underwater light climate. Limnol Oceanogr 52:1188-1194

Lizotte MP (2001) The contributions of sea ice algae to Antarctic marine primary production. Am Zool 41:57-73

Lizotte MP, Sullivan CW (1991) Photosynthesis-irradiance relationships in microalgae associated with Antarctic pack ice: evidence for in situ activity. Mar Ecol Prog Ser 71:175-184

> Mackey KRM, Paytan A, Grossman AR, Bailey S (2008) A photosynthetic strategy for coping in a high-light, lownutrient environment. Limnol Oceanogr 53:900-913

> Masojídek J, Grobbelaar JU, Pechar L, Koblížek M (2001) Photosystem II electron transport rates and oxygen production in natural waterblooms of freshwater cyanobacteria during a diel cycle. J Plankton Res 23:57-66

Maykut GA (1985) The ice environment. In: Horner RA (ed) Sea ice biota. CRC Press, Boca Raton, FL, p. 21-82

> Onno Feikema W, Marosvölgyi MA, Lavaud J, van Gorkom HJ (2006) Cyclic electron transfer in photosystem II in the marine diatom Phaeodactylum tricornutum. Biochim Biophys Acta 1757:829-834

Palmisano AC, Beeler SooHoo J, Sullivan CW (1987) Effects of four environmental variables on photosynthesis-irradiance relationships in Antarctic sea-ice microalgae. Mar Biol 94:299-306

> Prasil O, Kolber Z, Berry JA, Falkowski PG (1996) Cyclic electron flow around Photosystem II in vivo. Photosynth Res 48:395-410

Ralph PJ, Gademann R (2005) Rapid light curves: a powerful tool to assess photosynthetic activity. Aquat Bot 82: 222-237

> Rasmus KE, Graneli W, Wangberg SA (2004) Optical studies in the Southern Ocean. Deep-Sea Res Part II 51: 2583-2597

Ritchie RJ (2006) Consistent sets of spectrophotometric chlorophyll equations for acetone, methanol and ethanol 
solvents. Photosynth Res 89:27-41

Roberts D, Craven M, Cai M, Allison I, Nash G (2007) Protists in the marine ice of the Amery Ice Shelf, East Antarctica. Polar Biol 30:143-153

Rozema J, Broekman R, Lud D, Huiskes A and others (2001) Consequences of depletion of stratospheric ozone for terrestrial Antarctic ecosystems: the response of Deschampsia antarctica to enhanced UV-B radiation in a controlled environment. Plant Ecol 154:103-115

Sakshaug E, Demers S, Yentsch CM (1987) Thalassiosira oceanica and T. pseudonana: two different photoadaptational responses. Mar Ecol Prog Ser 41:275-282

Strzepek RF, Harrison PJ (2004) Photosynthetic architecture differs in coastal and oceanic diatoms. Nature 431: 689-692

Thomas DN, Gleitz M (1993) Allocation of photoassimilated carbon into major algal metabolite functions: variation

Editorial responsibility: Matthias Seaman

Oldendorf/Luhe, Germany between two diatom species isolated from the Weddell Sea (Antarctica). Polar Biol 13:281-286

- Thomas DN, Baumann MEM, Gleitz M (1992) Efficiency of carbon assimilation and photoacclimation in a small unicellular Chaetoceros species from the Weddell Sea (Antarctica): influence of temperature and irradiance. J Exp Mar Biol Ecol 157:195-209

- Tilzer MM, Elbrächter M, Gieskes WW, Beese B (1986) Light-temperature interactions in the control of photosynthesis in Antarctic phytoplankton. Polar Biol 5: 105-111

> Wagner H, Jacob T, Wilhelm C (2006) Balancing the energy flow from captured light to biomass under fluctuating light conditions. New Phytol 169:95-108

Wilhelm C (1990) The biochemistry and physiology of lightharvesting processes in chlorophyll b- and chlorophyll ccontaining algae. Plant Physiol Biochem 28:293-306

Submitted: February 16, 2011; Accepted: July 11, 2011

Proofs received from author(s): September 3, 2011 